\title{
Emergence of Chloride as an Overlooked Cardiorenal Connector in Heart Failure
}

\author{
Amir Kazory $^{\mathrm{a}}$ Claudio Ronco ${ }^{\mathrm{b}, \mathrm{c}}$ \\ ${ }^{a}$ Division of Nephrology, Hypertension, and Renal Transplantation, University of Florida, Gainesville, FL, USA; \\ ${ }^{b}$ Department of Nephrology, San Bortolo Hospital and International Renal Research Institute of Vicenza (IRRIV), \\ Vicenza, Italy; ' Department of Medicine, University of Padova, Padova, Italy
}

\section{Keywords}

Sodium $\cdot$ Chloride $\cdot$ Cardiorenal $\cdot$ Heart failure $\cdot$ Congestion · Hypochloremia

\begin{abstract}
Several studies have recently challenged the sodium-centric view that has been dominating the field of heart failure (HF) and cardiorenal syndrome. The previously observed benefits of severe dietary restriction of salt do not seem to be consistently reproduced by contemporary studies. Moreover, there is evidence that too low intake may paradoxically lead to adverse outcomes in more advanced stages of HF. Facing the escalating controversy, investigators have shifted their focus from sodium to its often overlooked counter ion in salt, the chloride. Emerging data suggest that serum chloride levels could portend robust independent prognostic value in a wide range of HF syndromes possibly stronger than that of sodium. The untoward impact of hypochloremia on the outcomes could be mechanistically linked to renal tubular regulatory pathways, neurohormonal activation, and diuretic resistance. As such, it can be a potential target of therapy in this setting. In this article, the authors provide a brief overview of the role of serum chloride as a cardiorenal connector and explore the context in which the contemporary data should be interpreted. Implementation of predictive and
\end{abstract}

\section{KARGER}

(c) 2019 S. Karger AG, Basel

E-Mail karger@karger.com

www.karger.com/bpu therapeutic strategies incorporating the emerging evidence would be refined through discussion of nuances of such findings as well as their biological and clinical relevance.

(c) 2019 S. Karger AG, Basel

Sodium, the primary constituent of fluid homeostasis and the key determinant of extracellular volume, has been the focus of numerous investigations in the field of heart failure (HF). Over the last decades, a core principal in management of HF has been dietary modifications focusing on lower salt intake. However, more recent evidence has challenged the conventional sodium-centric view suggesting that higher salt intake may be without untoward consequences, and too low intake may paradoxically lead to adverse outcomes [1]. Some investigators have even used hypertonic saline solution to successfully treat acute HF [2]. Facing the escalating controversy, there have been calls for "a retreat from an unbridled and potentially harmful insistence on rigorous sodium restriction in those with symptomatic HF" [3]. This notion is perplexing and difficult to explain from a pathophysiologic perspective because of the known negative impact of increase in total body sodium on renal, cardiac, and vascular homeostasis. It is within this context that some investigators have shifted their focus from sodium to its often overlooked counter 
ion in salt, the chloride. The question is whether the unanticipated adverse consequences of severe salt restriction in HF could indeed be related to lower intake of this seemingly passive partner of sodium. As such, a whole host of recent studies have explored the prognostic value of serum chloride levels in the setting of HF [4-9]. In 2015, Grodin at al. [4] reported that serum chloride level on admission is a robust and independent predictor of mortality in acute $\mathrm{HF}$, and it may even have a stronger prognostic value than sodium. Comparable results were later reported in stable chronic HF, where lower serum chloride was independently and incrementally associated with an increased risk of death [5-7]. Similar to acute HF, the prognostic value of serum sodium was markedly diminished when chloride levels were entered into the models, suggesting a stronger role for chloride. These findings were confirmed for HF patients both with or without reduced ejection fraction $[8$, 9]. The 2 common themes in all these studies are (1) hypochloremia is an independent predictor of adverse outcomes in a wide range of HF syndromes and (2) its association with mortality seems to be stronger than that of hyponatremia.

The underlying mechanisms for these interesting and somewhat unexpected findings are not completely understood. Chloride has unique homeostatic roles that are distinct from sodium. It is the main modulator of renin secretion and tubuloglomerular feedback in the kidney and is the key regulator of sodium transport pathways in the loop of Henle and distal convoluted tubule. Hypochloremia triggers renin secretion and increases the activity of sodium-potassium-chloride cotransporter in the thick ascending limb of loop of Henle as well as thiazidesensitive sodium-chloride symporter in the distal tubule. As such, it could be hypothesized that low serum chloride level (as a surrogate for depleted total body chloride stores due to chronic use of diuretics) would interfere with regulatory mechanisms that facilitate renal excretory functions. Clinical data, albeit limited, support this pathophysiologic notion; hypochloremia is clearly linked to neurohormonal activation and diuretic resistance, leading to impaired decongestion in patients with $\operatorname{HF}[10,11]$.

If these relationships are causal, and chloride is not a mere marker but a mechanistically relevant pathogenic cardiorenal connector, it could represent a potential target of therapy in HF. Sodium-independent correction of hypochloremia would then be expected to portend a multitude of benefits such as increase in urinary sodium excretion, reduction in neurohormonal activation, and improved survival. The idea of supplementing chloride and exploring the outcomes is not novel. Several decades ago, the investigators tried to use sodium-free chloride supplementation to treat refractory fluid retention, although that line of research was not followed, in part due to wide availability of more efficient and safer diuretics $[12,13]$. More recently, a proof of concept study was undertaken to explore neurohormonal and cardiorenal effect of lysine chloride supplementation in 10 patients with stable HF and chronic use of diuretics [10]. The results were not consistently positive; while there were signals of efficient decongestion (e.g., hemoconcentration and weight loss), the investigators noted a paradoxical rise in plasma renin activity and did not observe any improvement in diuretic response. Pharmacological increase in serum chloride levels using acetazolamide is yet another way to explore this relationship. Acetazolamide increases serum chloride levels, independent of sodium, through inhibition of intracellular and luminal carbonic anhydrase in the proximal tubules. In the recently published Diamox to Increase the Urinary Excretion of Sodium: an Investigational Study in Congestive Heart Failure (DIURESIS-CHF) trial, patients with acute HF that were randomized to receive acetazolamide in addition to lower doses of loop diuretics experienced urinary sodium excretion and decongestion similar to those who received high dose loop diuretics alone (i.e., an increase in "loop diuretic efficacy") [14]. Acetazolamide in Decompensated HF with Volume Overload trial is designed to examine the impact of acetazolamide on decongestion when added to highdose loop diuretics in patients with acute HF [15].

So, what can we do with the data generated by this series of overall well-done studies, and how can their findings improve our understanding and inform our clinical practice?

First, we need to be cognizant that the majority of these data are coming either from retrospective studies or from unplanned post hoc data analysis of trials in which the changes in the level of serum chloride were not the original question nor the primary or secondary endpoint. Therefore, while highly consistent, they are fraught with inherent limitations of such analyses. They should be regarded as hypothesis-generating evidence, which needs to be further tested in large prospective trials with serial measurements of serum chloride.

Second, chloride is also involved in acid-based homeostasis and is tightly linked to changes in $\mathrm{PH}$. Therefore, future studies need to determine whether changes in $\mathrm{PH}$ could modulate the association of hypochloremia and clinical outcomes.

Third, in view of these findings, HF therapy trials need to examine the impact of their interventions on serum 
chloride levels and include it as a safety endpoint. Indeed, there should be a demand for reporting of the changes in chloride in such studies. Similarly, the contemporary risk prediction models of HF can be revisited to determine whether incorporation of serum chloride level would add to their predictive value.

Finally, despite biological plausibility and existing clinical suspicion of a pathogenic role for hypochloremia in the setting of HF, the findings of very few available interventional trials have so far not been overwhelmingly convincing. For the time being, serum chloride seems to identify a subset of HF patients with more advanced cardiorenal impairment who present with higher diuretic requirement and heavier comorbid burden.

\section{Disclosure Statement}

The authors have no conflict of interest regarding the content of this manuscript.

\section{Funding Sources}

No specific financial support was obtained for preparation of this article.

\section{Author Contributions}

Dr. Amir Kazory wrote the draft of the manuscript and Professor Ronco provided critical revision.

\section{References}

1 Doukky R, Avery E, Mangla A, Collado FM, Ibrahim Z, Poulin MF, et al. Impact of Dietary Sodium Restriction on Heart Failure Outcomes. JACC Heart Fail. 2016 Jan;4(1): 24-35.

2 Gandhi S, Mosleh W, Myers RB. Hypertonic saline with furosemide for the treatment of acute congestive heart failure: a systematic review and meta-analysis. Int J Cardiol. 2014 May;173(2):139-45.

3 Yancy CW. Sodium Restriction in Heart Failure: Too Much Uncertainty-Do the Trials. JAMA Intern Med. 2018 Dec;178(12):1700-1.

4 Grodin JL, Simon J, Hachamovitch R, Wu Y, Jackson G, Halkar M, et al. Prognostic Role of Serum Chloride Levels in Acute Decompensated Heart Failure. J Am Coll Cardiol. 2015 Aug;66(6):659-66.

5 Zhang Y, Peng R, Li X, Yu J, Chen X, Zhou Z. Serum chloride as a novel marker for adding prognostic information of mortality in chronic heart failure. Clin Chim Acta. 2018 Aug; 483:112-8.

6 Grodin JL, Verbrugge FH, Ellis SG, Mullens $\mathrm{W}$, Testani JM, Tang WH. Importance of Ab- normal Chloride Homeostasis in Stable Chronic Heart Failure. Circ Heart Fail. 2016 Jan;9(1):e002453.

7 Testani JM, Hanberg JS, Arroyo JP, Brisco MA, Ter Maaten JM, Wilson FP, et al. Hypochloraemia is strongly and independently associated with mortality in patients with chronic heart failure. Eur J Heart Fail. 2016 Jun;18(6):660-8.

8 Cuthbert JJ, Pellicori P, Rigby A, Pan D, Kazmi S, Shah P, et al. Low serum chloride in patients with chronic heart failure: clinical associations and prognostic significance. Eur J Heart Fail. 2018 Oct;20(10):1426-35.

9 Grodin JL, Testani JM, Pandey A, Sambandam K, Drazner MH, Fang JC, et al. Perturbations in serum chloride homeostasis in heart failure with preserved ejection fraction: insights from TOPCAT. Eur J Heart Fail. 2018 Oct;20(10):1436-43.

10 Hanberg JS, Rao V, Ter Maaten JM, Laur O, Brisco MA, Perry Wilson F, et al. Hypochloremia and Diuretic Resistance in Heart Failure: mechanistic Insights. Circ Heart Fail. 2016 Aug;9(8):e003180.
11 Ter Maaten JM, Damman K, Hanberg JS, Givertz MM, Metra M, O'Connor CM, et al. Hypochloremia, Diuretic Resistance, and Outcome in Patients With Acute Heart Failure. Circ Heart Fail. 2016 Aug;9(8):e003109.

12 Hilton JG, Kalinsky H. Potentiation of diuretic action of mercuhydrin by ammonium chloride. J Clin Invest. 1951 Oct;30(10):1105-10.

13 Rubin AL, Spritz N, Mead AW, Herrmann RA, Braveman WS, Luckey EH. The use of Llysine monomydrochloride in combination with mercurial diuretics in the treatment of refractory fluid retention. Circulation. 1960 Mar;21(3):332-6.

14 Verbrugge FH, Martens P, Ameloot K, Haemels V, Penders J, Dupont M, et al. Acetazolamide to increase natriuresis in congestive heart failure at high risk for diuretic resistance. Eur J Heart Fail. 2019 May, Epub ahead of print.

15 Mullens W, Verbrugge FH, Nijst P, Martens P, Tartaglia K, Theunissen E, et al. Rationale and design of the ADVOR (Acetazolamide in Decompensated Heart Failure with Volume Overload) trial. Eur J Heart Fail. 2018 Nov; 20(11):1591-600. 